Article

\title{
Three-Faceted Approach to Perceived Stress: A Longitudinal Study of Stress Hormones, Personality, and Group Cohesion in the Real-Life Setting of Compulsory Basic Military Training
}

\author{
Svajone Bekesiene ${ }^{1, *(\mathbb{D})}$, Rasa Smaliukiene ${ }^{1,2, * \mathbb{D}}$, Ramutè Vaičaitienè ${ }^{1}$, Asta Mažeikiené ${ }^{3}$, Gerry Larsson ${ }^{3,4,5}$, \\ Dovilè Karčiauskaité ${ }^{3}$ and Eglè Mazgelyte ${ }^{3}(\mathbb{D}$
}

Citation: Bekesiene, S.; Smaliukiene, R.; Vaičaitienè, R.; Mažeikienè, A.;

Larsson, G.; Karčiauskaite, D.;

Mazgelytė, E. Three-Faceted

Approach to Perceived Stress: A

Longitudinal Study of Stress

Hormones, Personality, and Group

Cohesion in the Real-Life Setting of

Compulsory Basic Military Training.

Sustainability 2022, 14, 1046. https://

doi.org/10.3390/su14031046

Academic Editor: Lotfi Aleya

Received: 9 December 2021

Accepted: 12 January 2022

Published: 18 January 2022

Publisher's Note: MDPI stays neutral with regard to jurisdictional claims in published maps and institutional affiliations.

Copyright: () 2022 by the authors. Licensee MDPI, Basel, Switzerland. This article is an open access article distributed under the terms and conditions of the Creative Commons Attribution (CC BY) license (https:// creativecommons.org/licenses/by/ $4.0 /)$.
1 General Jonas Zemaitis Military Academy of Lithuania, LT-10322 Vilnius, Lithuania; ramute.vaicaitiene@1ka.lt 2 Business Management Department, Vilnius Gediminas Technical University, LT-10223 Vilnius, Lithuania

3 Department of Physiology, Biochemistry, Microbiology and Laboratory Medicine, Institute of Biomedical Sciences, Faculty of Medicine, Vilnius University, LT-03101 Vilnius, Lithuania; asta.mazeikiene@mf.vu.lt (A.M.); gerry.larsson@fhs.se (G.L.); dovile.karciauskaite@mf.vu.lt (D.K.); egle.mazgelyte@mf.vu.lt (E.M.)

4 Department of Leadership and Command \& Control, Swedish Defence University, 11428 Stockholm, Sweden

5 Faculty of Social and Health Sciences, Inland University College of Applied Sciences, 2406 Elverum, Norway

* Correspondence: svajone.bekesiene@lka.lt (S.B.); rasa.smaliukiene@lka.lt (R.S.)

\begin{abstract}
Compulsory basic military training is characterized not only by being challenging but also by being stressful. Assuming a high frequency of perceived stress events as a negative outcome of training, this article provides evidence on how the perceived frequency of stressful situations is affected by three types of factors: (i) biological stress response variables measured by hair steroid hormone levels, (ii) personality traits measured using the Big Five personality test, and (iii) group cohesion measures in military squads. A total of 112 conscripts in 11 squads participated in the research at the beginning (T1), in the middle (T2), and at the end (T3) of compulsory basic military training. Hair steroid hormone levels (cortisol, cortisone, and dehydroepiandrosterone (DHEA)) levels were measured by liquid mass spectrometry; other data were collected using self-report questionnaires. The results of the Poisson regression analysis indicated that hair steroid hormone cortisol had a statistically significantly impact and could increase the perceived frequency of stressful situations by up to $1.317\left(\mathrm{e}^{0.275}, \mathrm{~T} 2\right)$ times. The concentrations of other hormones (cortisone $=1.157, \mathrm{e}^{0.146}, \mathrm{~T} 3$ and DHEA $=1.020, \mathrm{e}^{0.020}, \mathrm{~T} 3$ ) also had a statistically significant effect. Other factors had a decreasing effect on the frequency. Extraversion was significant with an effect of $0.907\left(\mathrm{e}^{-0.098}, \mathrm{~T} 2\right)$ and 0.847 $\left(\mathrm{e}^{-0.166}, \mathrm{~T} 3\right)$, while task cohesion had an effect of $0.946\left(\mathrm{e}^{-0.056}\right)$ and norm cohesion of $0.954\left(\mathrm{e}^{-0.047}\right)$. The research indicates that the three groups of factors affect the perceived frequency of stressful situations during compulsory basic military training, but their impacts are considerably different.
\end{abstract}

Keywords: perceived stress; military training; conscripts; hair steroid hormone; cortisol; personality traits; group cohesion; stress resilience; risk management

\section{Introduction}

Perceived stress determines the degree of confidence of a person in their ability to cope with stressful situations [1,2], decreases subjective happiness [3], and has a negative impact on human wellbeing. The importance of perceived stress measurements in the military has grown in Europe, with almost half of the countries in the region strengthening or renewing compulsory (basic) military training [4]. Each year, several thousands of young people (predominantly men) participate in compulsory basic military training where they have to adopt to a new environment, learn new skills, and live as soldiers for more than half a year, separated from their civil lives. This period is described not only as challenging but also as stressful. Previous research provides results on various military and individual-related 
causes of perceived stress during basic military training, and courses of stress resilience, such as the emotional stability of solders [4], their physical fitness [5], personal and group performance [6], social support [7], or group cohesion [8]. However, there is a lack of an integrated approach that combines the various causes of stress and stress resilience and leads to a successful and sustainable stress management. Therefore, we will first discuss three dominating domains on perceived stress in the military and then present the results of our research that attempts to fill the current research gap.

The most recent and promising research domain on perceived stress management is related to the measurement of hair steroid hormone levels as objective chronic stress biomarkers in soldiers during military training. Understanding the interconnection between hair steroid hormone levels and psychological stressors in the natural military-specific environment is expected to enable the targeting of sustainable stress management interventions during military training. It is a new and innovative research direction since little is known about cumulative hair steroid hormone levels and their impact on psychological factors. Previous studies revealed that threat perception activates the amygdala, which in turn stimulates the hypothalamic-pituitary-adrenal (HPA) axis [8]. Activation of the HPA axis results in the production of glucocorticoids such as cortisol and its inactive metabolite cortisone $[9,10]$. The physiological function of glucocorticoids is to mobilize resources to eliminate the threat. In addition to these two hormones, the steroid hormone dehydroepiandrosterone (DHEA) is released during stress [11]. Long-term secretion of steroid hormones may affect not only psychological but also physical health [12]. To date, only a few studies report findings related to stress hormone measurement during compulsory military training, and these findings indicate somewhat contradictory results: Boesch [13] did not report any statistically significant change in the variation of hair cortisol levels during basic military training, despite changes in perceived stress levels; meanwhile, research by Gifford et al. [14] indicates a positive adaptation of the HPA axis function during basic military training.

The second research domain on stress management in the military is related to the classical approach towards stress and personality and personal resilience to stress. Various traits scales are used to account for the multidimensional nature of personality and relate personality traits to perceived stress [15]. For example, Calum [16] developed a mental toughness inventory to identify the sensitivity to various stressors among soldiers. The military training environment is full of various stressors, characterized by fatigue [17], anxiety, and fear [18], and it involves improvised explosive devices, fire, cold, and other adverse conditions for living and acting. As research shows, different types of personalities react differently to this environment, for example, stress coping style [4], harm avoidance, and award dependence $[8,19]$ are shown to have an effect on stress levels during military training.

The third research domain is related to group cohesion, which is an important factor in the military in general and during military training in particular $[20,21]$. Group cohesion is a phenomenon that connects individuals to achieve their goal, especially when the group is under stress [22]. Group cohesion in military training has been shown to increase stress resilience [23] and decrease the level of stress among soldiers during military training [8,24,25] and during deployment [26]. According to Ragsdale [27], social support from peers has a favorable effect and leads to better physical and psychological health among soldiers.

Despite extensive research carried out in the field, the complexity of the causative factors that contribute to the level of perceived stress has not yet been elucidated. Recent research combines two of these three research domains, such as personality traits and variations in stress hormones, or group cohesion and hormonal reactions, to the social environment in military. There is still a lack of research that assesses stress during basic military training from a multifaceted perspective and links all three domains. This is an important research gap because stress is a multiphased phenomenon "characterized by 
different triggers, different responses, and affecting the whole body" [28]. Therefore, it is best captured by a combination of instruments [29].

To address the research gap, this paper provides evidence on how the perceived frequency of stressful situations is affected by three types of factors: (i) biological stress response variables measured by hair steroid hormone levels, (ii) personality traits measured using a classical Big Five personality test, and (iii) group cohesion variables in military squads. The purpose of the research is to identify the factors that determine the perceived frequency of stressful situations. The reported research is a longitudinal study conducted that covered the entire period of one round of compulsory military training (nine months) in one military battalion in Lithuania. After a review of the study design, the article continues explaining the data collection methods and measures. As for the data collection, a sample of a total of 112 soldiers at compulsory military service (conscripts) was selected. Two statistical models were developed to evaluate the collected data using the Poisson regression model and the negative binomial model. At the end of the paper, we present the results of the model testing and interpret them in the light of previous studies.

\section{Materials and Methods}

\subsection{Participants}

The research was part of an ongoing longitudinal study on stress management during compulsory military training and received ethical approval from the Vilnius Regional Biomedical Research Ethics Committee, Lithuania. A total of 112 participants (age 18-26 years) from 11 squads were recruited for the study during the first month of training. Exclusion criteria included the use of synthetic steroids and hair dyeing during the previous three months, as well as shaved head for hair sample collection. Most of the participants were male $(97.3 \%)$ with secondary or higher education $(92.8 \%)$. Considering that group identification in the military is defined as an identification with the squad [30] (the smallest military unit [31]), the participants were recruited by squads; a total of 11 squads were selected.

The anthropometric data of the participants was collected during the three stages of the research. Height, weight, and systolic and diastolic blood pressure were measured using portable devices; data on height and weight were recalculated into body mass index (BMI) for further analysis (see results in Table 1).

Table 1. Descriptive data for participants included in the models.

\begin{tabular}{|c|c|c|c|}
\hline Variable & $\begin{array}{l}\text { T1: M(SD) } \\
\text { N (\%) }\end{array}$ & $\begin{array}{l}\text { T2: M(SD) } \\
\text { N (\%) }\end{array}$ & $\begin{array}{l}\text { T3: M(SD) } \\
\text { N (\%) }\end{array}$ \\
\hline Number of stressful events during the last week & $3.96(8.46)$ & $4.08(8.54)$ & $3.92(8.61)$ \\
\hline \multicolumn{4}{|l|}{ Hair steroid hormones concentration (ng/g) } \\
\hline Cortisol & $4.46(3.41)$ & $3.75(2.14)$ & $3.26(1.63)$ \\
\hline Cortisone & $16.60(7.33)$ & $14.52(6.02)$ & $11.78(4.30)$ \\
\hline DHEA & $14.32(13.14)$ & $16.16(17.98)$ & $11.72(10.38)$ \\
\hline \multicolumn{4}{|l|}{ Personality traits (14-items Likert scale) } \\
\hline Extraversion & $10.03(1.83)$ & (not repeated) & (not repeated) \\
\hline Agreeableness & $9.62(2.06)$ & (not repeated) & (not repeated) \\
\hline Conscientiousness & $8.62(1.45)$ & (not repeated) & (not repeated) \\
\hline Emotional Stability & $8.58(1.87)$ & (not repeated) & (not repeated) \\
\hline Openness & $8.81(1.90)$ & (not repeated) & (not repeated) \\
\hline \multicolumn{4}{|l|}{ Squad cohesion (7-items Likert scale) } \\
\hline Interpersonal cohesion & $5.17(0.98)$ & $4.58(1.07)$ & $4.55(1.36)$ \\
\hline Task cohesion & $4.90(0.87)$ & $4.47(0.85)$ & $4.56(1.11)$ \\
\hline Norm cohesion & $5.29(1.31)$ & $4.82(1.37)$ & $4.97(1.44)$ \\
\hline
\end{tabular}


Table 1. Cont.

\begin{tabular}{|c|c|c|c|}
\hline Variable & $\begin{array}{c}\text { T1: M(SD) } \\
\text { N (\%) }\end{array}$ & $\begin{array}{c}\text { T2: M(SD) } \\
\text { N (\%) }\end{array}$ & $\begin{array}{c}\text { T3: M(SD) } \\
\text { N (\%) }\end{array}$ \\
\hline $\begin{array}{c}\text { Anthropometric data } \\
\text { Blood pressure }(\mathrm{mmHg}) \text {-Systolic } \\
\text { Blood pressure }(\mathrm{mmHg}) \text {-Diastolic } \\
\text { Body mass index (BMI) }\end{array}$ & $\begin{array}{c}123.22(13.31) \\
71.85(8.48) \\
23.45(2.90)\end{array}$ & $\begin{array}{l}130.00(13.62) \\
71.72(12.27) \\
24.38(2.56)\end{array}$ & $\begin{array}{c}125.69(18.98) \\
70.13(13.64) \\
24.16(2.44)\end{array}$ \\
\hline $\begin{array}{c}\text { Stressful events outside the military (yes }=1 / \text { no } \\
\text {-quarrels at home } \\
\text { a relationship that ended } \\
\text { other strong negative experiences }\end{array}$ & $\begin{array}{l}26(24.1) \\
14(13.0) \\
31(28.7)\end{array}$ & $\begin{array}{l}25(25.0) \\
13(13.0) \\
34(34.0)\end{array}$ & $\begin{aligned} 25 & (24.0) \\
8 & (7.7) \\
23 & (22.1)\end{aligned}$ \\
\hline Squad (from 1 to 11 ) & - & - & - \\
\hline Chronic illnesses $($ yes $=1 /$ no $=0$ ) & $5(4.6)$ & $6(6.0)$ & $6(5.8)$ \\
\hline Smoking $($ every day $=1 ;$ seldom $=2 ;$ no $=3$ ) & $\begin{array}{l}42(38.9) \\
35(32.4) \\
31(28.7)\end{array}$ & $\begin{array}{l}39(39.0) \\
31(31.0) \\
30(30.0)\end{array}$ & $\begin{array}{l}38(36.5) \\
34(32.7) \\
32(30.8)\end{array}$ \\
\hline
\end{tabular}

Notes: T1-the first time dataset at the beginning of training; T2-the second time dataset in the middle of training; T3- the third time dataset at the end of training.

\subsection{Procedures and Measures}

Data were collected three times: during the first month of training (T1), when conscripts were adopting to military rules and battalion environment; in the middle of the training period (T2); and finally, at the end of training (T3) before the final examinations. Data collection took place during the COVID-19 pandemic when additional rules for social distancing were in place.

\subsubsection{Hair Sampling and Hair Steroid Hormones Analysis}

Hair samples were collected scalp-near from a posterior vertex position at the back of the head. As the average hair growth rate is $1 \mathrm{~cm} / \mathrm{month}$ [32], a collected one centimeter hair segment would contain steroid hormones deposited over the previous month prior to hair sampling. After hair collection, the samples were stored at room temperature in aluminum foil [33] and analyzed in laboratories of the Institute of Biomedical Sciences, Faculty of Medicine, Vilnius University. Hair hormone (cortisol, cortisone, DHEA) concentrations were detected using the ultra-high-performance liquid mass spectrometry (UHPLC-MS/MS) system (Shimadzu Corporation, Kyoto, Japan). Full details of the extraction procedure and analysis have been reported elsewhere by Mazeikiene et al. [34].

\subsubsection{Self-Reported Measures}

In this study, three clusters of self-reported data were used: (i) perceived frequency of stressful situations during one week, as a dependent variable in the study, (ii) assessment of personal characteristics, and (iii) group cohesion measurements. The study was carried out using printed questionnaires provided in Lithuanian.

- Perceived stress. Perceived stress was measured as a continuous variable and identified by asking participants 'how many times during the past week did you experience stress?' The response options were "I did not experience it, 1, 2, 3, 4, 5, 6, 7, 8, 9, 10, I have experienced it more than 10 times". Similar measurements were applied in stress research in other studies on perceived stress (see [35]).

- Personality. Personality was assessed using the Ten-Item Personality Inventory (TIPI) [35]. The TIPI is a measure of the Big Five (or the five-factor model)-the most widely accepted model of personality assessment [36]. TIPI identifies five personality traits: extraversion, when the person is sociable and active; agreeableness, when the person is soft-hearted and trusting; conscientiousness, when the person is organized and reliable; emotional stability, when the person is calm and relaxed; 
and openness, when the person is curious and creative [35,36]. The original TIPI was translated into Lithuanian. Before using the inventory for this study, forward and backward translation was used to overcome misunderstandings or unclear language [37] and, finally, it was tested in a pilot on a small sample. As alpha reliability is not applicable for this test [35], the mean scores and standard deviation of the answers were calculated: mean score for extraversion was $8.90( \pm 2.78)$; for agreeableness 9.79 ( \pm 2.07$)$; for conscientiousness $10.19( \pm 2.54)$; for emotional stability $10.05( \pm 2.64)$; and for openness $9.30( \pm 2.55)$. The test-retest for the mean effect was guaranteed by means of a minimum $90 \%$ credibility interval contested with pilot testing.

- Group cohesion. Group cohesion historically is considered to be the most important variable in small group leadership [38], and in military training cohesion is measured as a combination of three variables: (i) interpersonal cohesion, (ii) task cohesion, and (iii) norm cohesion [39]. Interpersonal cohesion indicates the attraction of an individual to the group [40]. In our study, we measured this variable using an inventory adopted from Salo [41] and Ohlsson et al. [42]. A sample item in the questionnaire: 'Most group members contribute to the decision-making in the group.' Task cohesion refers to the attraction of a person to the group as a common interest in the group task. The inventory was adopted from the Group Cohesion Scale-Revised [43]. A sample item in the questionnaire: 'In my squad, we easily accomplish tasks.' Finally, norm cohesion is about interpersonal relations and a person's attraction to the group because of common norms of behavior [40]. The inventory for task cohesion was created using respective items from previous research by Ohlsson et al. [42], Salo [41], and Treadwell et al. [43]. A sample item in the questionnaire: 'In my squad, anyone can ask questions and address problems'. All cohesion measures were constructed using the Likert 7-item scale (from one, meaning 'fully disagree', to seven, meaning 'fully agree'). An average Cronbach alpha for each of the cohesion inventory was as follows: for interpersonal cohesion, it was $0.893(\mathrm{~T} 1=0.872 ; \mathrm{T} 2=0.880 ; \mathrm{T} 3=0.928)$; for task cohesion, it was 0.782 $(\mathrm{T} 1=0.779 ; \mathrm{T} 2=0.738 ; \mathrm{T} 3=0.830)$; and for norm cohesion, it was 0.0.884 $(\mathrm{T} 1=0.869$; $\mathrm{T} 2=0.878 ; \mathrm{T} 3=0.904)$.

In addition, nonservice and nonsocial military environment-related stressors were used to assess perceived stress in a full spectrum. External stressors were evaluated to overcome incorrect interpretations of military training-related stressors in the event that a participant had stressful events outside of his military environment. A 2-item scale was used to assess events outside the military, such as domestic quarrels and other triggers that were not related to the military.

\subsubsection{Methods for Statistical Analysis}

The mean and standard deviation (SD) are presented as preliminary statistical results for quantitative variables. Absolute and relative frequencies were calculated for categorical variables. The normality of the variables was assessed using the Shapiro-Wilk's test. The level of statistical significance was set at 0.05 for the two-tailed testing. Repeated-measures MANOVA was performed to indicate whether there were significant differences with respect to the combined dependent variables between the independent variables (perceived frequency of stressful situations $\times$ time point). Bonferroni's post hoc comparison was used to identify significant differences between means. To test whether the assumption of sphericity was met, the Mauchly test was used, and the Greenhouse-Geisser adjustment was also performed if this assumption was violated [44]. The $p$-value was used to prove the statistically significant difference between conditions, and the partial eta squared $\left(\eta p^{2}\right)$ values were calculated as the magnitude of this difference. To report the measure of effect size $\left(\eta \mathrm{p}^{2}\right)$, the scale was used, and the calculated coefficients were considered small $(0.01)$, moderate $(0.06)$, and large (0.14) [45]. The relationship between variables was determined using the Pearson's correlation coefficient [46]. Finally, the Poisson regression model (PRM) and the negative binomial regression model (NBRM) were used for data evaluation. The Poisson regression model is used for a time-fixed period of events, and in our study, it 
was perceived stress occurring during one week. In addition, this method uses only nonnegative integer values such as the count of a perceived stressor (event). In the model, the count of perceived stress (events) during the last week is a dependent variable, while the independent variables in the model are as follows:

- Levels of hair steroid hormones: cortisol, cortisone, and the dehydroepiandrosterone steroid hormone (DHEA);

- Personality traits: extraversion, agreeableness, conscientiousness, emotional stability, and openness;

- Squad cohesion: interpersonal cohesion, task cohesion, and norm cohesion;

- Anthropometric data: blood pressure $(\mathrm{mmHg})$ — systolic and diastolic, body mass index (BMI);

- Stressful events outside of the military.

Negative binomial regression was used to overcome a limiting property of the Poisson distribution, where $\lambda$ equals both the mean and variance [47]. The negative binomial regression model is based on the distribution of a Poisson-gamma mixture distribution and allows the modeling of Poisson heterogeneity using a gamma distribution [48]. In this study, the negative binomial regression model was built using the same input variables as in the Poisson regression model. To assess the goodness-of-fit of different models and to choose the most parsimonious, a few well-known statistical measures were used: (1) Akaike's corrected information criterion (AICC); (2) Hurvich and Tsai's criterion (AICC);

(3) Schwarz's Bayesian criterion, also known as the Bayesian information criterion (BIC);

(4) Bozdogan's criterion (CAIC), which has a stronger penalty than AIC for models overparametrized [49,50]. Values of $p<0.05$ were considered statistically significant. Statistical modeling was performed using IBM SPSS $27 \mathrm{v}$ software.

\section{Results}

\subsection{Descriptive}

The descriptive statistics of the anthropometric, psychological, and health-related data are presented in Table 1.

Participants experienced stress four times a week on average. About $13 \%$ of the sample indicated that they did not experience stress during the week at the first (T1) and last (T3) time points, and 10\% of the sample during the second (T2) time point; meanwhile, only about $1 \%$ experienced stress more than ten times during a week at all three time points when data were collected. The repeated-measures MANOVA analysis tests of the between-subjects effects allowed us to identify that the significance values are less than 0.05 (see Sig. values in Table 2) and proved that there is an interaction effect. The detailed results for the tests of the between-subjects effects are presented in Table 2.

Table 2. Tests of between-subjects effects.

\begin{tabular}{|c|c|c|c|c|c|c|c|c|c|}
\hline Source & Measure & $\begin{array}{l}\text { Type IV Sum } \\
\text { of Squares }\end{array}$ & df & $\begin{array}{l}\text { Mean } \\
\text { Square }\end{array}$ & $\mathbf{F}$ & Sig. & $\begin{array}{c}\text { Partial Eta } \\
\text { Squared }\end{array}$ & $\begin{array}{l}\text { Noncent. } \\
\text { Parameter }\end{array}$ & $\begin{array}{c}\text { Observed } \\
\text { Power }\end{array}$ \\
\hline \multirow{2}{*}{ Intercept } & STR & 3065.756 & 1 & 3065.756 & 396.488 & 0.000 & 0.820 & 396.488 & 1.000 \\
\hline & $\mathrm{HCC}$ & 3996.269 & 1 & 3996.269 & 419.213 & 0.000 & 0.828 & 419.213 & 1.000 \\
\hline \multirow{2}{*}{ Squad (N) } & STR & 240.206 & 10 & 24.021 & 3.107 & 0.002 & 0.263 & 31.065 & 0.975 \\
\hline & $\mathrm{HCC}$ & 217.759 & 10 & 21.776 & 2.284 & 0.020 & 0.208 & 22.843 & 0.901 \\
\hline \multirow{2}{*}{ Error } & STR & 672.709 & 87 & 7.732 & & & & & \\
\hline & $\mathrm{HCC}$ & 829.352 & 87 & 9.533 & & & & & \\
\hline
\end{tabular}

Notes: Transformed variable: average; Computed using alpha $=0.05 ;$ STR-perceived frequency of stressful situations during one week; HCC-hair cortisol concentration (ng/g).

Tests of the between-subjects effects verified the statistically significant interaction ( $\mathrm{F}(3.107), p<0.05, \eta \mathrm{p}^{2}=0.263$ ) between squads (squad N) and stress (STR). Furthermore, statistically significant interaction $\left(\mathrm{F}(2.284), p<0.05, \eta \mathrm{p}^{2}=0.208\right)$ between squads (squad $\mathrm{N}$ ) and cortisol level (HCC)) was demonstrated (Table 2). 
Additionally, below are presented plots (Figure 1) to demonstrate the model-estimated means for the eleven squads for each of the three measurements (time point: T1, T2, and T3) for the perceived frequency of stressful situations and for hair cortisol levels. Separate lines are produced for each of the measurement times. The most frequent stressful situations were perceived at the beginning of training (T1, Figure 1a). Estimated marginal means measured in ng/g cortisol levels during the study (T1, T2, and T3) showed high variability between squads, especially at the beginning of training (Figure 1b).

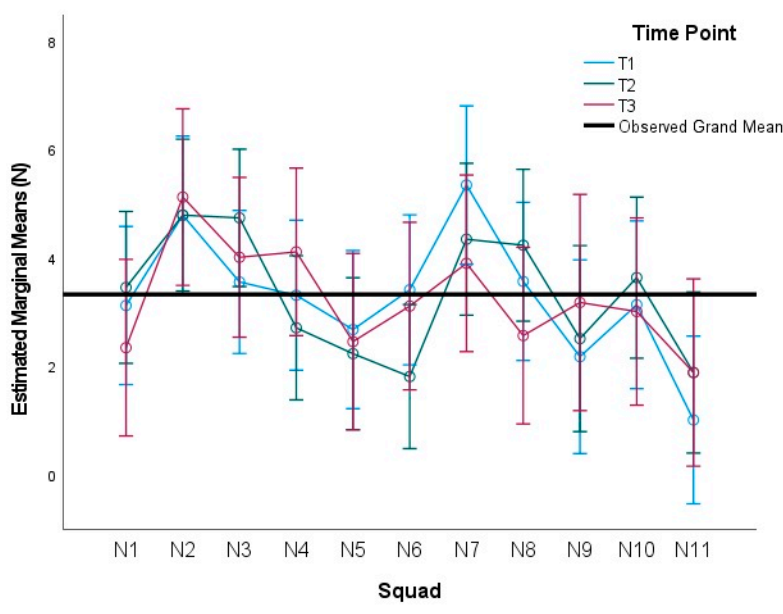

(a)

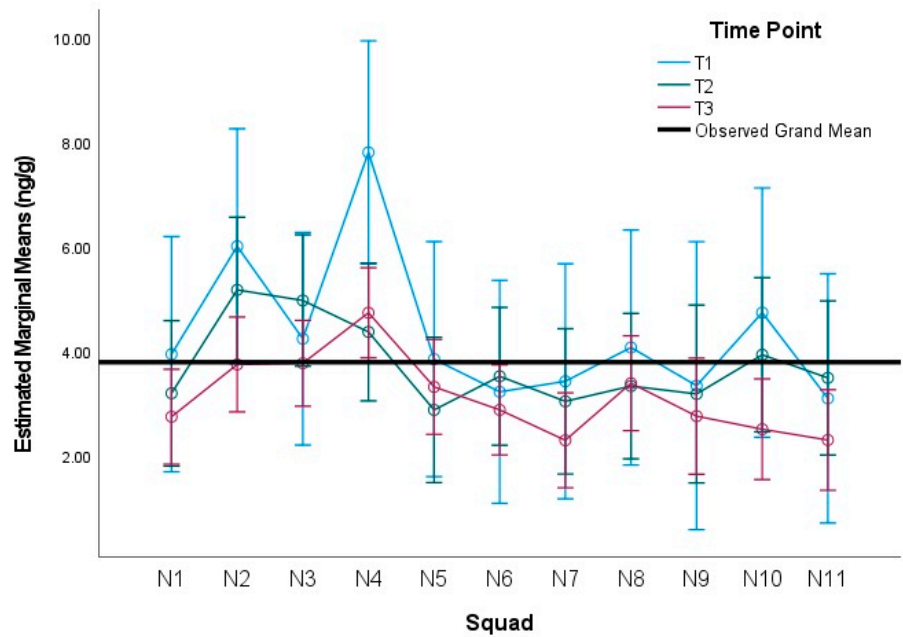

(b)

Figure 1. Estimated marginal means over the study (T1, T1, and T3) are presented, additionally are included error bars with confidence interval (95\%): (a) Estimated marginal means of experienced stress (events) (STR); (b) Estimated marginal means of cortisol (ng/g) (HCC).

\subsection{Model Estimation}

Poisson regression analysis was used to construct a prediction model for the perceived frequency of stressful situations during compulsory military training. To determine whether there is overdispersion in the Poisson regression model (PRM), the negative binomial regression model (NBRM) was created in addition with all settings equal. As the analysis shows, both models can be identified as statistically significant: the omnibus test provides a $p$-value at 0 for all models. To compare these models, goodness-of-fit was compared for models representing three time points, and finite sample corrected AIC (AICC) was taken into consideration. For all time points, AICC was smaller for Poisson regression models compared to those of the negative binomial regression model (Table 3); consequently, the Poisson regression models were chosen for further analysis.

Table 3. Goodness-of-fit for Poisson regression and negative binomial regression models.

\begin{tabular}{ccccccc}
\hline & \multicolumn{2}{c}{ T1 } & \multicolumn{3}{c}{ T2 } & T3 \\
\hline & PRM & NBRM & PRM & NBRM & PRM & NBRM \\
\hline Deviance & 138.557 & 43.754 & 136.388 & 37.059 & 184.537 & 48.592 \\
Scaled Deviance & 138.557 & 43.754 & 136.388 & 37.059 & 184.537 & 48.592 \\
Pearson Chi-Square & 131.438 & 33.025 & 133.441 & 29.749 & 217.841 & 41.341 \\
Scaled Pearson Chi-Square & 131.438 & 33.025 & 133.441 & 29.749 & 217.841 & 41.341 \\
Log Likelihood b & -213.326 & -240.916 & -206.858 & -229.272 & -228.887 & -231.775 \\
\hline
\end{tabular}


Table 3. Cont.

\begin{tabular}{|c|c|c|c|c|c|c|}
\hline & \multicolumn{2}{|c|}{ T1 } & \multicolumn{2}{|c|}{$\mathrm{T} 2$} & \multicolumn{2}{|c|}{ T3 } \\
\hline & PRM & NBRM & PRM & NBRM & PRM & NBRM \\
\hline $\begin{array}{l}\text { Akaike's Information Criterion } \\
\text { (AIC) }{ }^{a}\end{array}$ & 488.653 & 543.831 & 475.717 & 520.543 & 519.774 & 525.551 \\
\hline $\begin{array}{l}\text { Finite Sample Corrected AIC } \\
\text { (AICC) }{ }^{a}\end{array}$ & 514.758 & 569.937 & 504.893 & 549.720 & 547.330 & 553.106 \\
\hline $\begin{array}{l}\text { Bayesian Information } \\
\text { Criterion }(\mathrm{BIC})^{\mathrm{a}}\end{array}$ & 571.799 & 626.978 & 556.477 & 601.304 & 601.751 & 607.527 \\
\hline Consistent AIC (CAIC) ${ }^{a}$ & 602.799 & 657.978 & 587.477 & 632.304 & 632.751 & 638.527 \\
\hline
\end{tabular}

Notes: Dependent variable: CEMS (number of stressful events during the last week); ${ }^{a}$. Information criteria are in smaller-is-better form; ${ }^{b}$. The full log-likelihood function is displayed and used in computing information criteria; T1 - the first time dataset at the beginning of training; T2 - the second time dataset in the middle of training; T3 - the third time dataset at the end of training; PRM-Poison regression model; NBRM-negative binomial regression model.

Table 4 presents the parameter estimates using the Poisson regression model. The importance of the variables changed over time:

- The effects of hair steroid hormones. The level of all hair steroid hormones (cortisol, cortisone, and DHEA) has become highly statistically important $(p<0.001)$ in the model from the second time point (T2 and T3). It turns out that each additional cortisol concentration unit (measured in $\mathrm{ng} / \mathrm{g}$ ) is associated with an increase in the perceived frequency of stressful situations of different levels: $1.317\left(\mathrm{e}^{0.275}\right)$ in T2, $0.657\left(\mathrm{e}^{0.420}\right)$ in T3, and insignificant in T1. For example, for a person with twice the level of cortisol, the perceived frequency of stressful situations can increase by a factor of 1.317 on average at the middle of training. Other stress hormones also show a highly significant effect: changes in the cortisone concentration can increase the perceived frequency of stressful situations by $0.916\left(\mathrm{e}^{-0.086}\right)$ and $1.157\left(\mathrm{e}^{0.1469}\right)$ in T2 and T3, respectively, while DHEA can increase by $1.013\left(\mathrm{e}^{0.013}\right)$ and $1.020\left(\mathrm{e}^{0.020}\right)$, respectively.

- The effects of personality traits. Extraversion had a statistically significant $(p<0.05)$ negative effect in the middle (T2) and at the end (T3) of military training, and each additional point for extraversion was associated with a decrease in the perceived frequency of stressful situations, of $0.907\left(\mathrm{e}^{-0.098}\right)$ and $0.847\left(\mathrm{e}^{-0.166}\right)$, for the respective time points.

- The effect of group cohesion. Task cohesion had a statistically significant higher $(p<0.001)$ impact rate $\left(0.946, \mathrm{e}^{-0.056}\right)$ than other elements of group cohesion, as well as hair steroid levels and personality traits, at the beginning of compulsory basic military training (T1); however, it became insignificant in the later stages (T2 and T3) and was substituted by norm cohesion in T3. These findings indicate that group cohesion decreased the perceived frequency of stressful situations, and the frequency may change by $0.946\left(\mathrm{e}^{-0.056}\right)$ and $0.954\left(\mathrm{e}^{-0.047}\right)$ times while effected by task cohesion (in T1) and norm cohesion (in T2), respectively.

Note that the composition of some squads, the absence of chronic illnesses, and stressful events outside the military had statistically significant impact rates $(p<0.05)$ in the model for the beginning of military training (T1). The significance of these variables disappeared during the subsequent time points. In the middle of training (T2) and at the end of training (T3), the anthropometric data had significant $(p<0.001)$ impact rates $(p<0.001)$ in the model (Table 4$)$. 
Table 4. Parameter estimate using Poisson regression model.

\begin{tabular}{|c|c|c|c|c|c|c|}
\hline \multirow[b]{2}{*}{ Parameter } & \multicolumn{2}{|c|}{ T1 } & \multicolumn{2}{|c|}{ T2 } & \multicolumn{2}{|c|}{ T3 } \\
\hline & B & $\begin{array}{c}\text { Wald } \\
\text { Chi-Square }\end{array}$ & B & $\begin{array}{c}\text { Wald } \\
\text { Chi-Square }\end{array}$ & B & $\begin{array}{c}\text { Wald } \\
\text { Chi-Square }\end{array}$ \\
\hline (Intercept) & $5.363 * *$ & 23.965 & 0.615 & 0.343 & -1.567 & 2.357 \\
\hline $\begin{array}{l}\text { Hair steroid hormones } \\
\text { concentration }(\mathrm{ng} / \mathrm{g})\end{array}$ & & & & & & \\
\hline Cortisol & 0.015 & 0.396 & $0.275^{* *}$ & 17.596 & $-0.420 * *$ & 27.025 \\
\hline Cortisone & -0.016 & 1.919 & $-0.086^{* *}$ & 12.133 & $0.146^{* *}$ & 18.087 \\
\hline DHEA & -0.003 & 0.297 & $0.013^{* *}$ & 17.320 & $0.020 * *$ & 11.190 \\
\hline \multicolumn{7}{|l|}{ Personality traits } \\
\hline Extraversion & -0.027 & 0.423 & $-0.098^{*}$ & 5.832 & $-0.166^{* *}$ & 15.265 \\
\hline Agreeableness & 0.056 & 2.759 & -0.008 & 0.050 & 0.051 & 2.514 \\
\hline Conscientiousness & -0.063 & 2.160 & -0.071 & 2.453 & -0.048 & 0.900 \\
\hline Emotional Stability & -0.036 & 1.027 & 0.028 & 0.546 & 0.099 & 5.748 \\
\hline Openness & -0.018 & 0.192 & $0.105 *$ & 5.890 & 0.025 & 0.294 \\
\hline Squad cohesion & & & & & & \\
\hline Interpersonal cohesion & 0.009 & 1.154 & -0.011 & 2.807 & 0.012 & 1.669 \\
\hline Task cohesion & $-0.056^{* *}$ & 14.645 & -0.021 & 2.526 & -0.019 & 1.961 \\
\hline Norm cohesion & -0.019 & 2.976 & $-5.876 \times 10^{-5}$ & 0.000 & $-0.047^{* *}$ & 14.415 \\
\hline \multicolumn{7}{|l|}{ Anthropometric data } \\
\hline Blood pressure (EQS)- Systolic & 0.006 & 1.247 & 0.021 & 17.525 & $0.001^{* *}$ & 0.038 \\
\hline Blood pressure (EQS)- Diastolic & -0.015 & 4.319 & -0.010 & 2.602 & $-0.020^{* *}$ & 11.435 \\
\hline Body mass index (BMI) & -0.015 & 0.431 & 0.036 & 2.322 & $0.196^{* *}$ & 51.627 \\
\hline \multicolumn{7}{|l|}{ Stressful events outside military } \\
\hline quarrels at home (yes) & $0.368 *$ & 5.459 & -0.190 & 1.330 & -0.554 & 9.122 \\
\hline quarrels at home (no) & $0^{\mathrm{a}}$ & & $0^{\mathrm{a}}$ & & $0^{\mathrm{a}}$ & \\
\hline relationship that ended (yes) & -0.361 & 3.028 & 0.071 & 0.106 & 0.509 & 4.199 \\
\hline relationship that ended (no) & $0^{\mathrm{a}}$ & & $0^{\mathrm{a}}$ & & $0^{\mathrm{a}}$ & \\
\hline $\begin{array}{l}\text { other strong neg. } \\
\text { experiences (yes) }\end{array}$ & $0.317 *$ & 5.173 & 0.222 & 2.168 & 0.176 & 1.358 \\
\hline $\begin{array}{l}\text { other strong neg. } \\
\text { experiences (no) }\end{array}$ & $0^{\mathrm{a}}$ & & $0^{\mathrm{a}}$ & & $0^{\mathrm{a}}$ & \\
\hline \multicolumn{7}{|l|}{ Other } \\
\hline Chronic illnesses (no) & $-1.127 *$ & 28.778 & -0.512 & 3.290 & -0.058 & 0.032 \\
\hline Chronic illnesses (yes) & $0^{a}$ & & $0^{a}$ & & $0^{\mathrm{a}}$ & \\
\hline Smoking (no) & 0.027 & 0.028 & -0.040 & 0.060 & 0.038 & 0.052 \\
\hline Smoking (seldom) & 0.224 & 1.682 & -0.117 & 0.459 & -0.071 & 0.171 \\
\hline Smoking (every day) & $0^{a}$ & & $0^{\mathrm{a}}$ & & $0^{\mathrm{a}}$ & \\
\hline Squad N1 & -0.159 & 0.154 & -0.494 & 1.933 & -0.323 & 0.863 \\
\hline Squad N2 & 0.181 & 0.308 & -0.023 & 0.005 & 0.342 & 1.085 \\
\hline Squad N3 & $1.044^{* *}$ & 10.748 & -0.234 & 0.479 & 0.677 & 4.179 \\
\hline Squad N4 & 0.443 & 2.132 & 0.436 & 2.449 & 0.135 & 0.167 \\
\hline Squad N5 & $1.391^{* *}$ & 31.603 & 0.267 & 0.895 & 1.145 & 11.976 \\
\hline Squad N6 & 0.522 & 3.046 & -0.411 & 1.576 & 0.948 & 9.363 \\
\hline Squad N7 & 0.537 & 2.744 & 0.024 & 0.004 & 0.553 & 2.795 \\
\hline Squad N8 & $0.857 * *$ & 6.990 & -0.482 & 2.308 & 0.814 & 5.806 \\
\hline Squad N9 & 0.293 & 1.138 & -0.236 & 0.792 & 0.733 & 7.383 \\
\hline Squad N10 & 0.593 * & 4.272 & $0.553 *$ & 4.296 & 0.776 & 6.373 \\
\hline Squad N11 & $0^{\mathrm{a}}$ & & $0^{a}$ & & $0^{\mathrm{a}}$ & \\
\hline (Scale) & $1^{b}$ & & & & $1^{b}$ & \\
\hline
\end{tabular}

Notes: Dependent variable: Number of stressful events during the last week; Wald Chi-square is significant at the ${ }^{*} p<0.05$ or ${ }^{* *} p<0.001$; T1 - the first time dataset at the beginning of training; T2 — the second time dataset in the middle of training; T3- the third time dataset at the end of training; ${ }^{a}$. Set to zero because this parameter is redundant; ${ }^{b}$. Fixed at the displayed value.

\section{Discussion}

The current study investigated the three-faceted approach to perceived stress and examined how biological stress response variables, measured by hair steroid hormone levels, personality traits, and group (squad) cohesion, contribute to the perceived frequency of stressful situations in the real-life settings of compulsory basic military training. The study has shown that these three elements statistically significantly explain why conscripts experience events unequally even though they are under homogeneous stressful conditions.

In line with other studies on perceived stress and research on hair hormones, the study provides additional evidence of dependence between these variables. Previous studies provide quite contractionary results on this dependence and indicate a [51] decrease [14] and no change [13] in cortisol concentrations in the hair during compulsory basic military training, as well as a significant [14] and nonsignificant [13] associations between perceived 
stress levels and cortisol levels. The present study provides more clarity in interpreting the controversial findings, as the level of hair cortisol explains the variability in the perceived frequency of stressful situations in the middle and at the end of compulsory basic military training but has no effect on the variability at the beginning of training, when the conscripts are adapting to the new environment. The detected increase in the impact rates is true, not only for the hair hormone cortisol, but also for the other two hair steroid hormonescortisone and DHEA. To our knowledge, this is the first study to measure the levels of cortisone and DHEA hair steroids in relation to perceived stress in the real-life settings of compulsory basic military training.

Although it may be obvious that personality traits contribute to perceived stress, the military training environment creates specific situations where specific personal traits are manifested [51]. Studies in the general population indicate that neuroticism and conscientiousness are significant predictors of perceived stress level [52]. Our findings seem to contradict general population studies and provide evidence that openness and, to some level, emotional stability contribute to the perceived frequency of stressful situations, while extraversion decreases its frequency during military training.

The stress experienced by soldiers is expected to decrease when soldiers receive social support by acting in coherent groups. Group cohesion is one of the most significant small group properties in the military [21], while it works as a stress buffer in a stressful environment [26]. As found by Ahronson and Cameron [23], task and social cohesion are inversely associated with psychological distress among Canadian military employees. Furthermore, cohesion had a moderating effect on the relationship between stress perception and the adjustment of military life found in the Korean army [53]. Our study provides evidence that group cohesion is significant in reducing the perceived frequency of stressful situations for conscripts. In detail, task cohesion is shown to decrease the perceived frequency of stressful situations at the beginning of military training, while it is norm cohesion at the end of training. Still, it should be noted that this effect is relatively small.

Several limitations should be noted when interpreting the findings of this study. First, data were collected during the COVID-19 pandemic, when conscripts had fewer physical contacts with their family, friends, and loved ones. This circumstance may have reduced the effect of other (nonmilitary) stressors and increased the effect of military-specific stressors in the study. Thus, the application of findings is limited to specific circumstances that may be less relevant under a nonpandemic environment. Second, the country-specific military culture is considered a limitation, as the research was carried out only in Lithuania. The contradictory results obtained in conscripts' studies in Germany [14] and Switzerland [13] show that the research carried out in one country may lack generalization. Third, the data set used in this study is composed of objective data (hair steroid hormone level measurements and anthropometric data) and subjective data (perceived frequency of stressful situations, self-assessment of personal traits, and subjective evaluation of group cohesion). Due to social desirability, participants can underestimate or overestimate subjective factors.

\section{Conclusions}

This study expands our knowledge of perceived stress during compulsory basic military training and provides evidence regarding the variables that contribute to the perceived frequency of stressful situations. The study confirms the theoretical construct according to which the perceived frequency of stressful situations is influenced by three components: hair steroid hormone - cortisol, cortisone, and DHEA — concentrations, dominating personality traits, and group cohesion in squads. The hair cortisol concentration has a statistically significant impact, and it is found that each additional cortisol concentration unit (measured in $\mathrm{ng} / \mathrm{g}$ ) is associated with an increase in the perceived frequency of stressful situations of up to $1.317\left(\mathrm{e}^{0.275}, \mathrm{~T} 2\right)$ times at the middle of training. Concentrations of other hormones also had a statistically significant effect $(p<0.001)$ in the middle and at the end of training ( cortisone $=1.157, \mathrm{e}^{0.146}, \mathrm{~T} 3$ and DHEA $=1.020, \mathrm{e}^{0.020}, \mathrm{~T} 3$ ). Other factors had a decreasing effect on the perceived stress frequency. Extraversion was significant in the middle and at 
the end of service, with an effect of $0.907\left(\mathrm{e}^{-0.098}\right)$ and $0.847\left(\mathrm{e}^{-0.166}\right)$, respectively, while task cohesion, with an effect of $0.946\left(\mathrm{e}^{-0.056}\right)$, was significant at the beginning of training, and norm cohesion, with an effect of $0.954\left(\mathrm{e}^{-0.047}\right)$, was significant at the end of training.

Author Contributions: Conceptualization by R.S., R.V. and S.B.; methodology by A.M., R.S., R.V., S.B., G.L. and D.K.; software by S.B.; validation by R.S, A.M., D.K. and S.B.; formal analysis by S.B., A.M., E.M. and D.K.; investigations by R.S. and S.B; resources by R.S., R.V., D.K. and E.M.; data curation by R.S. and E.M.; writing for original draft preparation by R.S. and S.B.; writing for review and editing by R.V., G.L., A.M., D.K. and E.M.; visualization by S.B.; supervision by R.S. and A.M.; project administration by R.S.; and funding acquisition by R.S. All authors have read and agreed to the published version of the manuscript.

Funding: This research was funded by the Research Council of Lithuania (LMTLT) under project agreement no. S-MIP-20-59; the principal investigator of the grant was Rasa Smaliukiene. The publication was partly supported by General Jonas Žemaitis Military Academy of Lithuania, as a part of the Study Support Project "Research on the Management of Security and Defence Institutions of Small States".

Institutional Review Board Statement: The study was approved by the Vilnius Regional Biomedical Research Ethics Committee protocol \# 2020/10-1275-754.

Informed Consent Statement: Informed consent was obtained from all subjects involved in the study.

Data Availability Statement: The data supporting results are archived in the National Open Access Research Data Archive (MIDAS) at www.midas.lt (accessed on: 1 November 2021).

Conflicts of Interest: The authors declare no conflict of interest. The funder had no role in the design of the study; in the collection, analyses, or interpretation of the data; in the writing of the manuscript, or in the decision to publish the results.

\section{References}

1. Lazarus, R.S. Stress and Emotion: A New Synthesis; Springer: Berlin/Heidelberg, Germany, 1999; ISBN 9780826102614.

2. Lee, J.; Eunyoung, K.; Vwachholtz, A.; Kim, E. The effect of perceived stress on life satisfaction. Korean J. Youth Stud. 2016, 23, 29-47. [CrossRef] [PubMed]

3. Dhingra, V.; Dhingra, M. Effect of perceived stress on psychological well-being of health care workers during COVID 19: Mediating role of subjective happiness. Eur. J. Mol. Clin. Med. 2020, 7, 3683-3701.

4. Delahaij, R.; Van Dam, K. Coping with acute stress in the military: The influence of coping style, coping self-efficacy and appraisal emotions. Pers. Individ. Differ. 2017, 119, 13-18. [CrossRef]

5. Müller-Schilling, L.; Gundlach, N.; Böckelmann, I.; Sammito, S. Physical fitness as a risk factor for injuries and excessive stress symptoms during basic military training. Int. Arch. Occup. Environ. Health 2019, 92, 837-841. [CrossRef]

6. Beckner, M.E.; Main, L.; Tait, J.L.; Martin, B.J.; Conkright, W.R.; Nindl, B.C. Circulating biomarkers associated with performance and resilience during military operational stress. Eur. J. Sport Sci. 2021, 1-15. [CrossRef]

7. Overdale, S.; Gardner, D. Social Support and Coping Adaptability in Initial Military Training. Mil. Psychol. 2012, 24, 312-330. [CrossRef]

8. Scholarworks, S.; Townsend, C.L. Perceived Selectivity as a Moderator of Cohesion and Resilience in USAF EOD Operators. Ph.D. Thesis, Walden University, Minneapolis, MN, USA, 2020.

9. Lehrer, H.M.; Steinhardt, M.A.; Dubois, S.K.; Laudenslager, M.L. Perceived stress, psychological resilience, hair cortisol concentration, and metabolic syndrome severity: A moderated mediation model. Psychoneuroendocrinology 2020, 113, 104510. [CrossRef]

10. Musana, J.W.; Cohen, C.R.; Kuppermann, M.; Gerona, R.; Wanyoro, A.; Aguilar, D.; Santos, N.; Temmerman, M.; Weiss, S.J. Association of differential symptoms of stress to hair cortisol and cortisone concentrations among pregnant women in Kenya. Stress 2019, 23, 556-566. [CrossRef] [PubMed]

11. Schury, K.; Koenig, A.M.; Isele, D.; Hulbert, A.L.; Krause, S.; Umlauft, M.; Kolassa, S.; Ziegenhain, U.; Karabatsiakis, A.; Reister, F; et al. Alterations of hair cortisol and dehydroepiandrosterone in mother-infant-dyads with maternal childhood maltreatment. BMC Psychiatry 2017, 17, 213. [CrossRef]

12. Richardson, C.M.E.; Rice, K.G.; Devine, D.P. Perfectionism, emotion regulation, and the cortisol stress response. J. Couns. Psychol. 2014, 61, 110-118. [CrossRef]

13. Boesch, M.; Sefidan, S.; Annen, H.; Ehlert, U.; Roos, L.; Van Uum, S.; Russell, E.; Koren, G.; La Marca, R. Hair cortisol concentration is unaffected by basic military training, but related to sociodemographic and environmental factors. Stress 2014, 18, 35-41. [CrossRef] [PubMed] 
14. Gifford, R.M.; O’Leary, T.J.; Double, R.L.; Wardle, S.L.; Wilson, K.; Boyle, L.D.; Homer, N.Z.M.; Kirschbaum, C.; Greeves, J.P.; Woods, D.R.; et al. Positive adaptation of HPA axis function in women during 44 weeks of infantry-based military training. Psychoneuroendocrinology 2019, 110, 104432. [CrossRef]

15. Grant, S.; Langan-Fox, J. Occupational stress, coping and strain: The combined/interactive effect of the Big Five traits. Pers. Individ. Differ. 2006, 41, 719-732. [CrossRef]

16. Arthur, C.A.; Fitzwater, J.; Hardy, L.; Beattie, S.; Bell, J. Development and Validation of a Military Training Mental Toughness Inventory. Mil. Psychol. 2015, 27, 232-241. [CrossRef]

17. Martin, K.; Périard, J.; Rattray, B.; Pyne, D.B. Physiological Factors Which Influence Cognitive Performance in Military Personnel. Hum. Factors J. Hum. Factors Ergon. Soc. 2019, 62, 93-123. [CrossRef]

18. Gonzalez, G.L.C.; Valencia, L.E.P.; Trefftz, H. Use of a Serious Game for Teaching Operations Programming: Students' Perceptions. In Proceedings of the 2018 International Conference on Computational Science and Computational Intelligence (CSCI), Las Vegas, NV, USA, 12-14 December 2018; IEEE: New York, NY, USA, 2018; pp. 667-670.

19. Elsass, W.P.; Fiedler, E.; Skop, B.; Hill, H. Susceptibility to Maladaptive Responses to Stress in Basic Military Training Based on Variants of Temperament and Character. Mil. Med. 2001, 166, 884-888. [CrossRef]

20. Smaliukienè, R.; Smaliukien, E.R. Public-private partnership and its influence to corporate social responsibility. Public Policy Adm. 2005, 1, 69-76.

21. Prause, G.; Tuisk, T.; Olaniyi, E.O. Between sustainability, social cohesion and security. Regional development in North-Eastern Estonia. Entrep. Sustain. Issues 2019, 6, 1235-1254. [CrossRef]

22. Siebold, G.L. The Essence of Military Group Cohesion. Armed Forces Soc. 2007, 33, 286-295. [CrossRef]

23. Ahronson, A.; Cameron, J.E. The Nature and Consequences of Group Cohesion in a Military Sample. Mil. Psychol. 2007, 19, 9-25. [CrossRef]

24. Hadid, A.; Evans, R.K.; Yanovich, R.; Luria, O.; Moran, D.S. Motivation, cohesion, satisfaction, and their relation to stress fracture among female military recruits. Graefe's Arch. Clin. Exp. Ophthalmol. 2008, 104, 329-335. [CrossRef]

25. Griffith, J. Multilevel Analysis of Cohesion's Relation to Stress, Well-Being, Identification, Disintegration, and Perceived Combat Readiness. Mil. Psychol. 2002, 14, 217-239. [CrossRef]

26. Bierman, A.; Kelty, R. Subjective Cohesion as Stress Buffer Among Civilians Working with the Military in Iraq and Afghanistan. Armed Forces Soc. 2017, 44, 238-260. [CrossRef]

27. Ragsdale, J.M.; Kochert, J.F.; Beehr, T.A. News from the front: A monthly study on stress and social support during a military deployment to a war zone. J. Occup. Health Psychol. 2021, 26, 326-338. [CrossRef]

28. Shackleton, G.L. Towards a biochemical approach to occupational stress management. Heliyon 2021, 7, e07175. [CrossRef] [PubMed]

29. Štěpáníková, I.; Baker, E.; Oates, G.; Bienertova-Vasku, J.; Klánová, J. Assessing Stress in Pregnancy and Postpartum: Com-paring Measures. Matern. Child Health J. 2020, 24, 1193-1201. [CrossRef] [PubMed]

30. García-Guiu, C.; Moya, M.; Molero, F.; Moriano, J.A. Transformational leadership and group potency in small military units: The mediating role of group identification and cohesion. Rev. Psicol. Trab. Las Organ. 2016, 32, 145-152. [CrossRef]

31. Britt, T.W.; Wilson, C.A.; Sawhney, G.; Black, K.J. Perceived unit climate of support for mental health as a predictor of stigma, beliefs about treatment, and help-seeking behaviors among military personnel. Psychol. Serv. 2020, 17, 141-150. [CrossRef]

32. Wennig, R. Potential problems with the interpretation of hair analysis results. Forensic. Sci. Int. 2000, 107, 5-12. [CrossRef]

33. Mayer, S.E.; Lopez-Duran, N.L.; Sen, S.; Abelson, J.L. Chronic stress, hair cortisol and depression: A prospective and longitudinal study of medical internship. Psychoneuroendocrinology 2018, 92, 57-65. [CrossRef] [PubMed]

34. Mazeikiene, A.; Bekesiene, S.; Karčiauskaite, D.; Mazgelytè, E.; Larsson, G.; Petrènas, T.; Kaminskas, A.; Songailienė, J.; Vaičaitienè, R.; Utkus, A.; et al. He Association between Endogenous Hair Steroid Hormones and Military Environ-ment-Related Factors in a Group of Military Conscripts. Int. J. Environ. Res. Public Health 2021, 18, 12239. [CrossRef] [PubMed]

35. Gosling, S.D.; Rentfrow, P.J.; Swann, W.B., Jr. A very brief measure of the Big-Five personality domains. J. Res. Pers. 2003, 37, 504-528. [CrossRef]

36. Nunes, A.; Limpo, T.; Lima, C.F.; Castro, S.L. Short Scales for the Assessment of Personality Traits: Development and Vali-dation of the Portuguese Ten-Item Personality Inventory (TIPI). Front. Psychol. 2018, 9, 461. [CrossRef] [PubMed]

37. Tsang, S.; Royse, C.F.; Terkawi, A. Guidelines for developing, translating, and validating a questionnaire in perioperative and pain medicine. Saudi J. Anaesth. 2017, 11, S80-S89. [CrossRef]

38. Carron, A.V.; Brawley, L.R. Cohesion: Conceptual and Measurement Issues. Small Group Res. 2000, 31, 89-106. [CrossRef]

39. Carless, S.A.; De Paola, C. The Measurement of Cohesion in Work Teams. Small Group Res. 2000, 31, 71-88. [CrossRef]

40. Van Vianen, A.E.; De Dreu, C.K. Personality in teams: Its relationship to social cohesion, task cohesion, and team performance. Eur. J. Work. Organ. Psychol. 2001, 10, 97-120. [CrossRef]

41. Salo, M. Determinants of Military Adjustment and Attrition During Finnish Conscript Service; University of Helsinki: Helsinki, Finland, 2008.

42. Ohlsson, A.; Hedlund, E.; Larsson, G. Examining the relationship between personality, organizational political skill and perceived team performance in a multinational military staff exercise context. J. Mil. Stud. 2016, 7, 24-30. [CrossRef]

43. Treadwell, T.; Lavertue, N.; Kumar, V.K.; Veeraraghavan, V. The Group Cohesion Scale-Revised: Reliability and Validity. Int. J. Action Methods Psychodrama Ski. Train. Role Play. 2001, 54, 3-12. 
44. Greenhouse, S.W.; Geisser, S. On methods in the analysis of profile data. Psychometrika 1959, 24, 95-112. [CrossRef]

45. Lakens, D. Calculating and reporting effect sizes to facilitate cumulative science: A practical primer for $t$-tests and ANOVAs. Front. Psychol. 2013, 4, 863. [CrossRef] [PubMed]

46. Hopkins, W.G. A New View of Statistics. 2014. Available online: https://complementarytraining.net/wp-content/uploads/2013 /10/Will-Hopkins-A-New-View-of-Statistics.pdf. (accessed on 12 November 2021).

47. Sellers, K.F.; Premeaux, B. Conway-Maxwell-Poisson regression models for dispersed count data. Wiley Interdiscip. Rev. Comput. Stat. 2021, 13, e1533. [CrossRef]

48. Bekesiene, S.; Hubacekf, M.; Bures, M. Modelling Possibilities of the Vehicle Movement on Communication Network for Defense and Crisis Management. In Proceedings of the 2019 International Conference on Military Technologies (ICMT), Brno, Czech Republic, 30-31 May 2019; IEEE: New York, NY, USA, 2019; pp. 1-6.

49. Foster, D.P.; George, E.I. The Risk Inflation Criterion for Multiple Regression. Ann. Stat. 1994, 22, 1947-1975. [CrossRef]

50. Cavanaugh, J.E.; Neath, A.A. The Akaike information criterion: Background, derivation, properties, application, interpretation, and refinements. WIREs Comput. Stat. 2019, 11, e1460. [CrossRef]

51. Skoglund, T.H.; Brekke, T.-H.; Steder, F.B.; Boe, O. Big Five Personality Profiles in the Norwegian Special Operations Forces. Front. Psychol. 2020, 11, 747. [CrossRef]

52. Czerwiński, S.; Atroszko, P. Scores of short and free scale for Big Five explain perceived stress at different stages of life: Validity, reliability and measurement invariance of the Polish adaptation of Mini-IPIP. Curr. Issues Pers. Psychol. 2020, 8, 73-82. [CrossRef]

53. Ha, J.H.; Jue, J.; Jang, Y. The Relationship Between Army Soldiers' Perceived Stress and Army Life Adjustment: Focusing on the Mediating Effect of Stress Response and the Moderating Effect of Cohesion. Mil. Med. 2020, 185, e1743-e1749. [CrossRef] [PubMed] 